\title{
Flexible 3D Nanoporous Graphene for Desalination and Bio- decontamination of Brackish Water via Asymmetric Capacitive \\ Deionization
}

\begin{abstract}
Ahmed G. El-Deen ${ }^{\text {a, b, e, }, \text { Remko M. Boom }}{ }^{\mathrm{c}}$, Hak Yong Kim ${ }^{\text {d }}$, Hongwei Duan ${ }^{\mathrm{a}}$, Mary B. Chan-Park ${ }^{\mathrm{a}, \mathrm{b}, *}$ and Jae-Hwan Choi ${ }^{\mathrm{f}, *}$

${ }^{a}$ School of Chemical and Biomedical Engineering, Nanyang Technological University, 62 Nanyang Drive, Singapore 637459 (Singapore)

${ }^{\mathrm{b}}$ Centre for Antimicrobial Bioengineering, Nanyang Technological University, Singapore 637459

c Food Process Engineering Laboratory, Agrotechnology and Food Sciences Group, Wageningen University, The Netherlands

${ }^{d}$ BioNanosystem and Bin Fusion Department, Chonbuk National University, Jeonju 561-756, South Korea

${ }^{\mathrm{e}}$ Renewable Energy Science and Engineering Department, Faculty of Postgraduate Studies for Advanced Sciences (PSAS), Beni- Suef University, Beni-Suef 62511, Egypt

${ }^{\mathrm{f}}$ Department of Chemical Engineering, Kongju National University, 1223-24 Cheonan-daero, Seobuk-gu, Cheonan, Chungnam 331-717, Republic of Korea
\end{abstract}

*Corresponding author. Tel.: +82 41521 9362; fax: +82 415212640.

*E-mail address: ag.kalil@,jbnu.ac.kr; jhchoi@,kongju.ac.kr;mbechan@ntu.edu.sg 

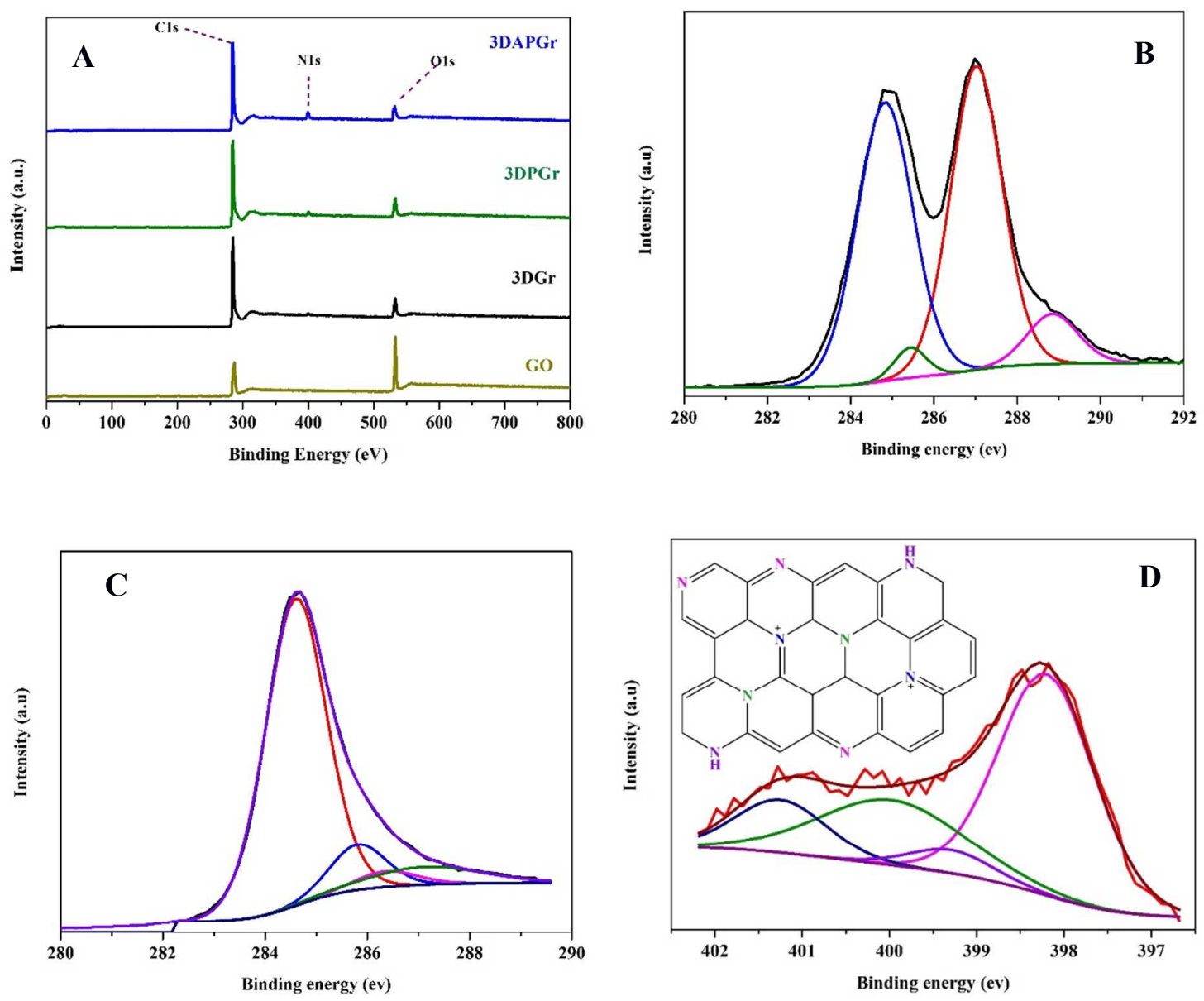

Figure S1 XPS survey for the fabricated porous graphene based CDI electrode (A) and high resolution of C1s of GO (B), C1s and N1s of 3DAPGr (C.D). 


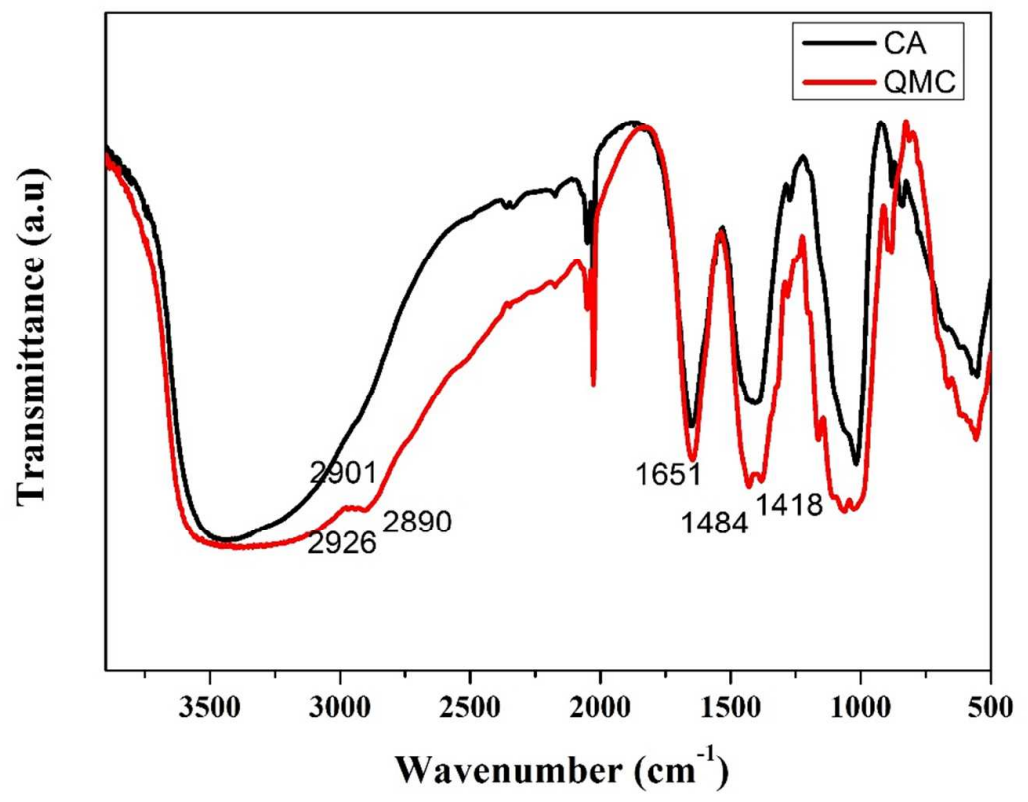

Figure S2. FTIR of Cellulose acetate (CA) and Quaternary ammonium cellulose (QMC). 


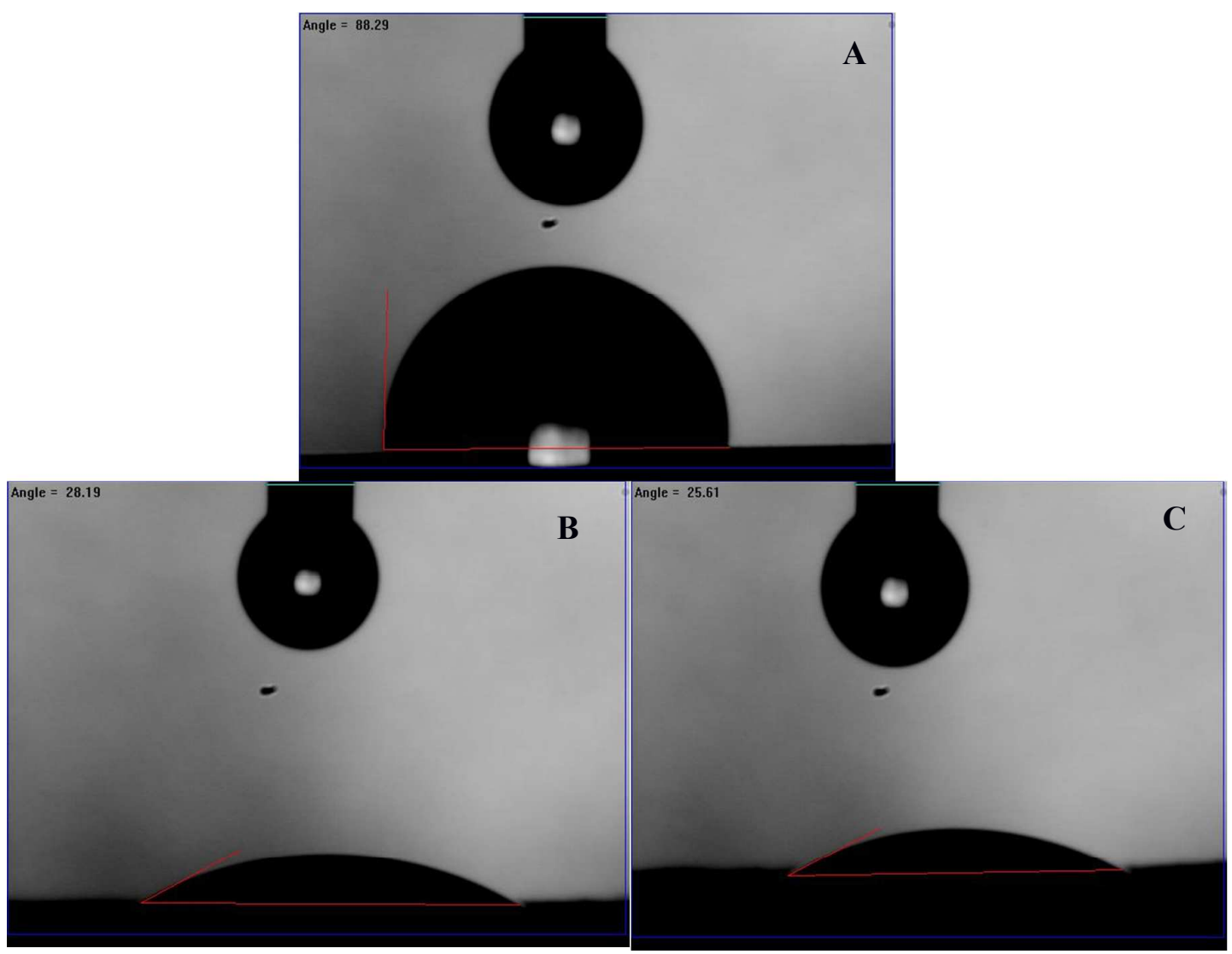

Figure S3. Water contact angel for the fabricated electrode (A) 3DAPGr, (B) Q3DAPGr and C-3DAPGr electrode (C). 

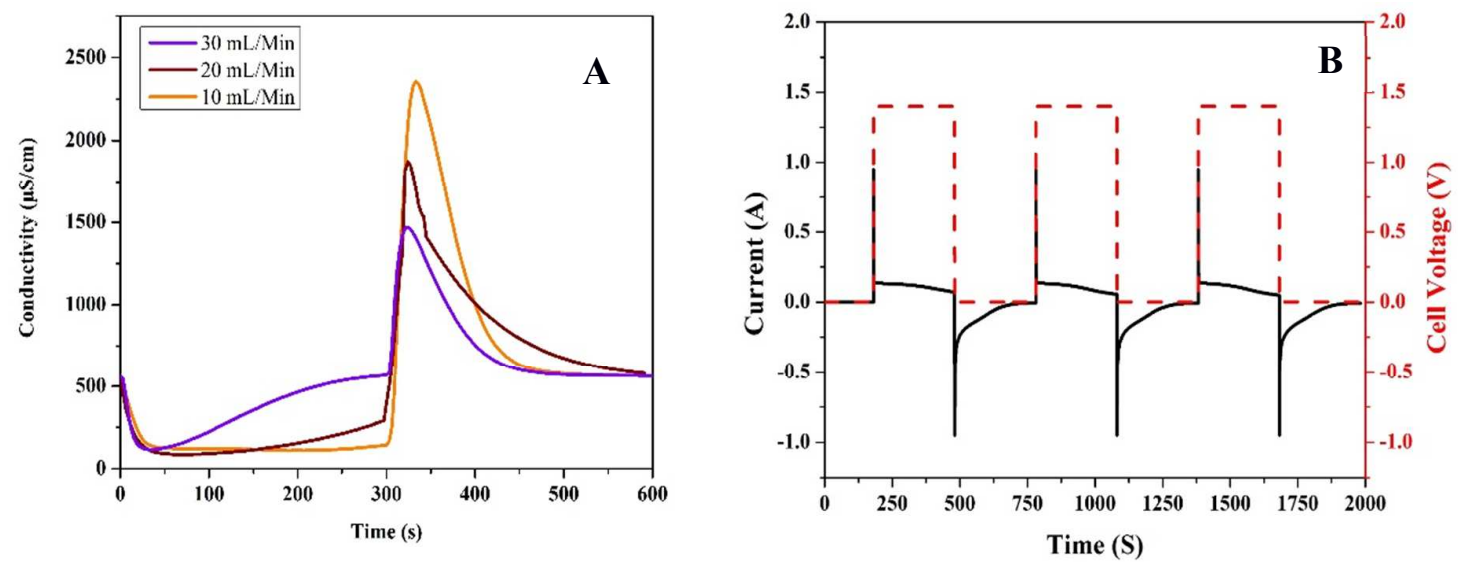

Figure S4. CDI profiles for the Asym-QC 3DAPGr cell configuration at $1.4 \mathrm{~V}$ under different flow rate of 10, 20 and $30 \mathrm{~mL} / \mathrm{min}$ using SP- mode(A), Current changes verses input voltage during CDI process (B). 